\title{
Postoperative Nausea and Vomiting: 168 Years in Review
}

\author{
Joseph DiLustro* \\ Pressure Point, Inc., USA
}

Submission: December 15, 2016; Published: February 21, 2017

*Corresponding author: Joseph DiLustro, chairmen and CEO, Pressure Point, Inc., Email: therapeutics101@verizon.net

\begin{abstract}
DiLustro is the inventor of the multi-modal PONV Pressure Point therapy technique. Research and expanding use of this technique has proven to be a safe and effective multi-modal choice in PONV management. The company's acu-stimulation adhesive technique enhances anesthesiology benefits, such as, nausea and vomiting prophylaxis, elimination of expensive or risk-based rescue drug therapies and broader patient satisfaction, with no reported adverse effects. This evidence-based anesthetic-related technique provides an extended duration (72 hours) of PONV therapy to support Enhanced Recovery after Surgery (ERAS) protocol reimbursement practices.
\end{abstract}

\section{Introduction}

The introduction of volatile agents such as ether and chloroform in the 1840s was heralded as the most important medical innovation. However, the phenomenon of postoperative nausea and vomiting (PONV) became evident within only two years, and remains as a major complication for general anesthesia today. The first report on the devastating effect of PONV was published in 1848 by Dr. John Snow, a British anesthesiology pioneer who described his findings on this disturbing complication associated with surgery and anesthesia. Until his untimely death in 1858 at the age of 45 years, Dr. Snow was one of the foremost authorities in the administration of anesthesia [1].

During the ether era of 1846 to 1950 , the incidence of PONV was reported to be as high as $75-80 \%$ [2]. During this time in an effort to reduce the incidence of PONV, neuroleptic drugs were considered the most efficacious pharmacotherapy because of the inherent anti-emetic properties of this drug class. The first prophylactic use of an anti-emetic drug derived from the neuroleptic phenothiazine drug class was introduced in the 1880s [2]. Neuroleptic phenothiazine drugs block receptors in the central nervous system's (CNS) dopamine pathways which mitigate the effects of nausea.

\section{The Emergence of Anti-Emetic Therapy}

Almost half a century later, the use of new neuroleptic class of promethazine drugs emerged to further reduce the incidence of PONV [3]. Promethazine pharmaceuticals have profound antiemetic properties due to antagonizing histamine- 1 receptors in the CNS. However, because of untoward sedative effects, the use of this drug class was very limited for postoperative antiemetic prophylaxis because it delayed emergence from general anesthesia. Twenty years later, the next phase of anti-emetic therapy emerged. The neuroleptic class of chlorpromazine drugs antagonized a variety of receptors in the CNS.3 Unfortunately the drug's neuroleptic effect elicits both sedation and hypotension which limited its use in PONV management.

\section{The First Century of Anti-Emetic Therapy}

After the discovery of anesthetic-induced PONV, clearly the distress of surgical patients were not positive experiences evidenced during the first 100 years of the practice of medicine. By 1950, anesthesia practice changed to reduce the residual effects of drugs that contributed to PONV. Six years later, halothane, a non-flammable volatile gas developed for general inhalational anesthesia was introduced, replacing noxious anesthetics such as ether. Halothane contributed to a substantially-reduced PONV incidence after emergence from inhalational general anesthesia. Over the next 25 years, halothane was commonly administered in clinical anesthesia practice [4]. During the 1980s in the US, the administration of these early inhalational anesthetic agents became less appealing and were gradually phased out as improved volatile agents were developed such as isoflurane, desflurane, or sevoflurane.

\section{Evolution of PONV Prophylaxis}

At the end of the 20th century, advancements in the prophylactic use of anti-emetic drug therapy had not progressed 
mainly because of the serious risks of drug side effects such as profound sedation. In the early 1990s, anesthetists preferred a novel anesthetic agent: propofol. This hypnotic drug is administered intravenously (IV) as an induction drug or total IV delivery for anesthetic maintenance. In addition, IV propofol has anti-emetic properties that help reduce the effects of PONV [4]. Propofol is still today's choice as a general anesthetic agent in contemporary anesthesia practice.

\section{Novel Anti-Emetics}

Fortunately, in the mid-1990s, anesthesiologists focused on the promising new class of anti-emetics, the $5-\mathrm{HT}_{3}$-serotonin receptor antagonists introduced to oncologists for the treatment of chemotherapy-induced nausea and vomiting (CINV). These drugs block the $5-\mathrm{HT}_{3}$-serotonin receptors, which are highlyspecific emetogenic receptors in the chemoreceptor trigger zone (CTZ). Clinically, the 5- $\mathrm{HT}_{3}$-receptor antagonists produced an anti-emetic effect with little to no side effects, with a relatively good safety profile [5].

Since the mid-1990s, the traditional anti-emetic therapy chosen by most anesthesiologists and certified registered nurse anesthetists (CRNAs) to mitigate the incidence of PONV, include the serotonin 5 - $\mathrm{HT}_{3}$-receptor antagonists such as ondansetron $\left(\right.$ Zofran $^{\circledR}$ ), granisetron $\left(\right.$ Kytril $^{\circledR}$ ) or dolasetron (Anzemet ${ }^{\circledR}$ ). In addition, anesthesiologists and CRNAs use a multi-modal strategy that includes dexamethasone, a steroid drug that is known to have anti-emetic properties to enhance the efficacy of 5 - $\mathrm{HT}_{3}$ prophylactic therapy. Due to multiple emetic receptors that can be stimulated during anesthesia, the management of PONV requires multi-modal strategies using a combination of antiemetic drugs to help ameliorate PONV such as 5- $\mathrm{HT}_{3}$-receptor antagonists, especially in the high-risk patient population [5]. These type of anti-emetics help block the serotonin receptors throughout the gut and CNS that trigger nausea and vomiting.

\section{Short Duration of PONV Prophylaxis Efficacy}

Much evidence published over the last 15 years describes the limited efficacy and duration of action of the traditional 5 - $\mathrm{HT}_{3}$-receptor antagonists, including dexamethasone used in a multi-modal anti-emetic therapy regimen. Initially anesthetists thought that $5-\mathrm{HT}_{3}$ antagonists should be preemptively administered, prior to the induction of anesthesia. However, because of the drug's relatively short duration of PONV efficacy, later practice evolved to administer prophylaxis just prior to emergence of anesthesia, at the completion of surgery during patient skin closure.

Comparatively, the traditionally standard use of $5-\mathrm{HT}_{3}$ receptor antagonists, such as ondansetron (or in combination with dexamethasone), currently offer some PONV prevention as well as a higher safety profile compared to other prophylactic drugs. Despite the import of the evidence-based practice of multimodal anti-emetic drug prophylaxis, some surgical patients continue to experience protracted PONV symptoms which can also interfere with patients' recovery at home especially after outpatient surgery [6-8]. Clinically, an estimated 25\%-30\% of surgical patients are still impacted by PONV after general anesthesia subsequent to receiving prophylactic anti-emetic medications [9]. In addition, one-third or even up to $35 \%-49 \%$ of patients undergoing outpatient surgery experience nausea and vomiting after they are discharged. Largely because patients returning home from outpatient surgery do not have access to anti-emetic therapy $[9,10]$.

\section{Expanding Anti-Emetic Therapy}

The relatively new phenomenon known as post-discharge nausea and vomiting (PDNV) has become a significant concern to practitioners because of the growing number of outpatient and short-stay surgical procedures. Anesthesiologists, CRNAs, and especially peri-operative nurses continue to be confronted with patients' complications of PONV and PDNV, despite modifying dosages or combinations of anti-emetic therapy.

After discharge from outpatient surgery, extended antiemetic benefits are not solving the PDNV problem at home.7 Clinical options for achieving anti-emetic efficacy in the postdischarge period include newer anti-emetics which are either very expensive, such as aprepitant $\left(\right.$ Emend $\left.^{\circledR}\right)$, palonesetron $\left(\right.$ Aloxi $^{\circledR}$ ), or transdermal scopolamine [11]. However, the scopolamine patch may have the potential of temporarily imposing adverse quality of life issues (i.e., blurred vision or extremely dry mouth) [12].

Enhancing patient satisfaction, providing cost-benefits and minimizing drug side effects are paramount for a worthy solution to the recalcitrant PONV problem. Use of other clinicallydeveloped multi-modal PONV techniques that enable patients to overcome the anesthetic-induced difficulties associated with surgery can become part of a novel and efficacious multi-modal prophylaxis strategy for anti-emesis [13].

Effective emetic prophylaxis management today requires refinement for at-risk surgical patients who require enhanced protection against the episodic severity of further PONV and PDNV suffering. Current published PONV guidelines require an upgrade of additional PONV techniques to mitigate the effects of both post-operative problems. Over the last 15 years, evidence reveals that prophylactic drug therapy alone is not the complete solution in substantially preventing the incidence of PONV and PDNV. The PONV guidelines offer strategic insight into identifying at-risk surgical patients. However, the existing prophylactic multi-modal drug treatment strategy model has not resulted in a complete effect of a clear and definitive solution to extensively improving patient recovery from deleterious nausea and vomiting in the post-operative period [13].

The legacy of PONV prophylaxis today is compounded by the growing concern of PDNV occurrences at home for surgical 
patients. The implication for expanded anti-emetic coverage is readily apparent in view of current clinical PONV/PDNV events. Additional multi-modal PONV techniques are currently available to fill the vacuum of patient need due to inadequate efficacy of drug therapy. Clinically-proven and FDA approved prescription and/or over-the-counter (OTC) main stream, multi-modal PONV techniques implemented as part of the multi-modal anesthetic plan, would serve to improve overall PONV management conditions

The clear implication is that intervention other than further pharmacotherapy is necessary to reduce nausea and vomiting symptoms for surgery patients. Other clinically-proven, main stream multi-modal PONV techniques lead these efforts. Clearly a fundamental serious reevaluation is necessary to achieve an enhanced quality of PONV outcomes management compared to drug treatment options alone [13].

\section{PONV Pressure Point Therapy}

Pressure Point, Inc. is a global medical device company specializing in mainstream acu-point stimulation strips, which improve multi-modal anesthetic techniques associated with the complexity common problem of post-operative nausea and vomiting. The company introduced its Pressure Right ${ }^{\odot}$ acupressure point-stimulation product in 2011 after receiving market clearance from the FDA as a prescribed technique representing an essential part of the anesthetic plan for surgery patients. In 2014, Pressure Point subsequently received market clearance as an OTC technique for the prevention of nausea and vomiting.

As part of a multi-modal strategy for patients undergoing laparoscopic surgery, a high quality, randomized, double-blind, sham-controlled study reported that the use of Pressure Right $($ C demonstrated a statistically meaningful, absolute risk reduction of PONV for surgical patients as long as 72 hours postoperatively [14]. The study further confirmed the direct result of prophylaxis with Pressure Right ${ }^{\odot}$ revealed a multi-modal PONV effect to substantially reduce the main stream requirements for expensive rescue-drug therapies. As a result, a broader patient satisfaction with PONV prevention was reported among Pressure RightC study subjects.

Prior to the introduction of the multi-modal Pressure Right (C acu-stimulation strip in 2011 for the 72-hour prevention of PONV, a plethora of research had been published on the efficacy of acu-stimulation for PONV [14-16]. Several incipient versions of acu-stimulation offered significant benefits and few, if any risks. However, the early product models were limited in duration for multi-modal nausea prophylaxis for surgical use and patient suitability for PONV prevention.

Pressure Right's ${ }^{\circledR}$ adaptive adhesive technique uses $3 \mathrm{M}^{\mathrm{TM}}$ material that's been on the market since 1970, which is safe from skin irritation, blistering, or pain when applied to the skin for extended use.
The Pressure Right@ randomized, double-blind, shamcontrolled study effectively combined PC6 acustimulation and PONV antiemetic therapy versus antiemetic therapy and demonstrated improved PONV patient outcomes despite the use of an insensitive binary method (Yes or No) study response to assess postoperative nausea [14].

In a recent Cochrane review of PC6 acustimulation clinical data of at least 39 trials, 4622 participants, compared to sham treatment, it confirmed PC6 acustimulation techniques significantly reduced the incidence of nausea, vomiting and the need for rescue antiemetics postoperatively. The Cochrane author's conclusion recommends more high-quality trials involving the combination of acustimulation and antiemetic drug therapy compared to drug prophylaxis to determine the combination's clinical PONV therapy future impact [17].

Outside the US today, Pressure Point(C) has overseas distribution partners targeting the anesthetic market for prevention of PONV for at-risk surgical patients. Research and expanding use has proven Pressure Right(C) a high-quality competitive choice in PONV management.

\section{References}

1. Snow J (1991) On narcotics by the inhalation of vapours. Facsimile (Ed.), Royal Society of Medicine Services Ltd., London, pp. 1848.

2. Islam S, Jain PN (2004) Post-operative nausea and vomiting (PONV): A review article. Indian J Anaesth 48 (4): 253-258.

3. Rowbotham J (1992) Current management of postoperative nausea and vomiting. Br J Anaesth 46-59.

4. Raftery S, Sherry E (1992) Total intravenous anesthesia with propofol and alfentanyl protects against postoperative nausea and vomiting. Can J Anaesth 39(1): 37-40.

5. Gregory RE, Ettinger DS (1998) 5- $\mathrm{HT}_{3}$ receptor antagonists for the prevention of chemotherapy-induced nausea and vomiting-a comparison of their pharmacology and clinical efficacy. Drugs 55(2): 173-189.

6. White PF, O'Hara JF, Roberson CR, Wender RH, Candiotti KA (2008) The impact of current anti-emetic practices on patient outcomes: a prospective study on high-risk patients. Anesth Analg 107(2): 452458.

7. Chinnappa V, Chung F (2008) Post-dischage nausea and vomiting: An overlooked aspect of ambulatory anesthesia? Can J Anaesth 55(9): 565-571.

8. Gan TJ, Meyer TA, Apfel CC, Chung F, Davis PJ, et al. (2007) Society for Ambulatory Anesthesia guidelines for the management of postoperative nausea and vomiting. Anesth Analg 105(6): 1615-1628.

9. Hegarty AT, Buckley MA, McCaul CL (2016) Ambulatory anesthesia and postoperative nausea and vomiting: predicting probability. Ambulatory Anesthesia 3: 27-35.

10. Gan TJ (2016) New strategies to prevent nausea and vomiting after surgery. Special Outpatient Surgery Magazine Edition, Anesthesia 2023.

11. White PF, Tang J, Song D, Coleman JE, Wender RH, et al. (2007) Transdermal scopolamine: An alternative to ondansetron and droperidol for the prevention of postoperative emetic symptoms. Anesth Analg 104: 92-96. 
12. www.rxlist.com/transderm-scop-side-effects-drug-center.

13. White PF (2007) Use of alternative medical therapies in the perioperative period: is it time to get on board? Anesth Analg 104(2): 251-254.

14. White PF, Zhao M, Tang J, Wender RH, Yumul R, et al. (2012) Use of a disposable acupressure device as part of a multimodal anti-emetic strategy for reducing postoperative nausea and vomiting. Anesth Analg 115: 31-37.
15. Hickman Angela G, Bell Donald M, Preston John C. Acupressure and postoperative nausea and vomiting. AANA Journal 73(5): 379-385.

16. Lee A, Fan LTY (2009) Stimulation of the wrist acupuncture point $P_{6}$ for preventing postoperative nausea and vomiting. Cochrane Cochrane Database Syst Rev (2): CD003281.

17. Lee A, Chan SK, Fan LT (2015) Stimulation of the wrist acupuncture point PC6 for preventing postoperative nausea and vomiting. Cochrane Database Syst Rev 11: CD003281.

\section{Your next submission with Juniper Publishers will reach you the below assets}

- Quality Editorial service

- Swift Peer Review

- Reprints availability

- E-prints Service

- Manuscript Podcast for convenient understanding

- Global attainment for your research

- Manuscript accessibility in different formats ( Pdf, E-pub, Full Text, Audio)

- Unceasing customer service

Track the below URL for one-step submission https://juniperpublishers.com/online-submission.php 